\title{
Message from the new Editor-in-Chief
}

\section{Toshiyuki Hibiya}

(C) The Oceanographic Society of Japan and Springer 2011

It is my pleasure to announce that effective 1 April 2011, I succeeded Dr. Toshiro Saino of the Japan Agency for Marine-Earth Science and Technology as Editor-in-Chief of the Journal of Oceanography (JO). I would like to express my deepest respect and heartfelt gratitude for the tremendous efforts of Dr. Saino and the previous editorial board members of JO, who have greatly contributed to raising the international reputation of JO.

As already announced on the JO website, we have started using the online Editorial Manager ${ }^{\circledR}$ system on 1 April 2011, making it possible for authors to submit manuscripts via the Internet and track them through the review process. It also provides online peer-review services. Authors are requested to use Editorial Manager ${ }^{\circledR}$ for all submissions of new manuscripts. Key features include automatic conversion of authors' submissions into PDF format as well as supporting submissions in various file formats and with special characters. New instructions to authors for online submission are available at the JO website: http://www.springer.com/10872. I believe the introduction of the online system Editorial Manager ${ }^{\circledR}$ will significantly expedite the review processes and, most importantly, the publication of each manuscript.

One more important thing to be noted here is that submission categories of JO have been modified such that (1)
"Marine Biology" and "Microbiology" have been reorganized into "Marine Biology: Benthos", "Marine Biology: Plankton and Nekton", and "Marine Biology: Bacteria and Archaea", and (2) "Physical Oceanography: Remote Sensing, Surface Waves" has been divided into "Physical Oceanography: Remote Sensing" and "Physical Oceanography: Surface Waves, Experiments", both taking into account the rapid increase in the number of submitted manuscripts in these research fields.

In order to further strengthen the new editorial board, I am inviting several world-class leading scientists from abroad to join us. I believe that the new editorial board including the members from abroad can be finalized by the middle of May.

One of the great advantages of JO is that there is no page charge. I would like to encourage authors, especially young scientists, including graduate students, to submit their interesting manuscripts to JO. As the new Editor-in-Chief, I promise that I will do my best to further enhance the international reputation of JO. I greatly appreciate your continuing support for our journal.

Toshiyuki Hibiya

Editor-in-Chief

T. Hibiya $(\bowtie)$

Department of Earth and Planetary Science,

Graduate School of Science, The University of Tokyo,

Tokyo 113-0033, Japan

e-mail: hibiya@eps.s.u-tokyo.ac.jp 